\title{
O REFERENDO DAS ARMAS NO BRASIL Estratégias de campanha e comportamento do eleitor
}

\section{Luciana Fernandes Veiga Sandra Avi dos Santos}

O objetivo deste artigo é analisar o Referendo das Armas com foco nas estratégias de comunicação utilizadas pela Frente Parlamentar por um Brasil sem Armas (campanha do SIM) e pela Frente Parlamentar pelo Direito da Legítima Defesa (campanha do NÃO), expressas nas propagandas veiculadas pelo Horário Eleitoral (HE), e o efeito persuasivo que elas tiveram sobre os eleitores na hora da decisão do voto. O argumento a ser desenvolvido é o de que havia um cenário de representação política favorável à campanha do SIM no momento em que antecedia à veiculação da propaganda, mas que foi anulado pela retórica adotada pela campanha do NÃO. O sucesso da Frente pelo Direito da Legítima Defesa pode ser parcialmente explicado pela utilização de propagandas negativas para acionar valores e crenças

Artigo recebido setembro/2007

Aprovado em janeiro/2008 permanentes no eleitorado brasileiro, como a instabilidade dos direitos dos cidadãos e a percepção de ineficiência do Estado.

Para o estudo, foram analisados os programas eleitorais de televisão veiculados entre os dias 1 e 20 de outubro de 2005, às 13:00hs e às 20:30hs. Os spots, comerciais divulgados ao longo da programação, não foram avaliados. Os programas foram analisados a partir de uma adaptação do método desenvolvido por Figueiredo, Aldé, Bezerra e Jorge (2000). Tal metodologia, originalmente elaborada para a análise de spots eleitorais, teve de ser ajustada para se adequar ao estudo dos programas televisivos do referendo.

Para a avaliação da recepção adotou-se a técnica de painel com entrevistas em profundidade. Os participantes pertenciam a diferentes classes sociais e tinham idades variadas. Foram feitas três entrevistas com cada um dos participantes: a primeira, em agosto de 2005, antes da veiculação do 
Horário Eleitoral; a segunda, em outubro, durante a veiculação da propaganda; a última, no momento posterior à veiculação da propaganda, mas antes da votação.

Logo após a realização do referendo do desarmamento, uma série de artigos foi publicada a fim de explicar o fenômeno político. ${ }^{1}$ Todos os trabalhos utilizaram como justificativa a raridade do episódio e a reviravolta da intenção de voto dos eleitores. Ainda que possa parecer repetitivo, não há como avançar na análise do referendo sem mencionar tais aspectos.

No dia 23 de outubro de 2005, aproximadamente 122 milhões de eleitores foram submetidos à terceira consulta popular da história brasileira, sendo questionados em relação à pergunta: "O comércio de armas de fogo e munição deve ser proibido no Brasil? 1) NÃO; 2) SIM".

O primeiro referendo aconteceu em 1963, quando os cidadãos tiveram que optar pelo retorno ao presidencialismo ou a manutenção do regime parlamentarista. Em 1993, os eleitores voltaram a decidir sobre o sistema de governo em plebiscito. O número de consultas populares no país ainda é muito restrito particularmente se comparado com as realidades norte-americana e européia. A propósito, um caso paradigmático é a Califórnia. Neste estado, para que qualquer emenda constitucional já aprovada se efetive é preciso que ela receba a aprovação de dois terços da população em referendo. Na Comunidade Européia, com freqüência o instrumento vem sendo utilizado, uma série de questões têm sido decididas por consultas populares. Também a América Latina vem vivenciando a experiência de referendos, particularmente na Venezuela, sob o comando de Hugo Chaves, e na Bolívia, com Evo Morales. Assim, o interesse em analisar o referendo das armas já se justificaria pela constatação de que esse tipo de consulta é um instrumento legislativo cada vez mais utilizado em diversos países e ainda muito raro no Brasil.

Mas uma segunda questão, que só pôde ser observada posteriormente, serviu para tornar tal objeto ainda mais instigante, a saber, a mudança radical de opinião dos brasileiros sobre o tema em questão em um período de tempo muito curto. Vários institutos (Datafolha, Ibope, Sensus, entre outros) divulgaram pesquisas na véspera da campanha de TV, apontando para a expectativa da franca vitória da Frente Parlamentar por um Brasil sem Armas. ${ }^{2}$ Mas o resultado das urnas foi muito diferente. No dia do referendo, 36,06\% dos eleitores optaram pela proibição da venda de armas e munições e 63,94\% decidiram pela manutenção da comercialização.

De acordo com Lissovsky (2006), a brusca mudança de intenção de voto iniciou-se logo após o começo da divulgação da propaganda de televisão. Dois dias após o início da veiculação do Horário Eleitoral, o tracking da campanha do SIM já mostrava queda de sua vantagem sobre o adversário. De acordo com a série de pesquisas realizadas pelo instituto Ibope, a superação da campanha do NÃO sobre a campanha do SIM aconteceu em torno dos dias 12 e 13 de outubro, quando os surveys mostravam que $49 \%$ dos eleitores já pensavam em votar pelo NÃO e 45\% estavam dispostos a votar pelo SIM.

Por fim, a terceira justificativa para a realização deste trabalho está na existência de um movimento em defesa da ampliação do uso do instrumento de consulta popular. ${ }^{3}$ Caso esse movimento seja vitorioso, os cientistas políticos vão precisar se empenhar nessa nova área de estudo sobre o comportamento eleitoral.

Este texto está estruturado em quatro partes. Em um primeiro momento, pretende-se apresentar o conceito de Cenário de Representação Política - CR-P, descrevendo como ele estava sendo construído pela imprensa no momento anterior à veiculação do Horário Eleitoral do Referendo das Armas. Em um segundo momento, busca-se apresentar uma breve discussão sobre o conceito, o uso e o efeito persuasivo da propaganda negativa. Nesse sentido, será avaliado, ainda, como a campanha do NÃO utilizou tal retórica. Na terceira parte, objetiva-se analisar as mensagens divulgadas pelas campanhas. Por fim, procura-se mostrar como os eleitores incorporaram as mensagens de campanha a partir do Cenário de Representação do momento anterior à propaganda para então decidirem o seu voto.

\section{CR-P: o conceito e as contribuições para a explicação do referendo}

As teorias na área de comunicação e política vêm avançando muito desde que os pesqui- 
sadores deixaram de se preocupar com o efeito direto da mensagem sobre o receptor e passaram a enfatizar o efeito indireto da comunicação, que se dá necessariamente no ambiente informacional da audiência. Teorias como da agenda-setting e da espiral do silêncio vêm demonstrando grande potencial explicativo. ${ }^{4}$ Afinado com essa mesma tendência, encontra-se o conceito de Cenário de Representação da Política, CR-P, desenvolvido por Venício Lima (2004).

Baseado no conceito de hegemonia de Gramsci, Lima (2004) propõe que o cenário é um espaço onde o sentido da vida e das coisas é constituído. É nesse espaço que se realiza um conjunto de práticas e expectativas cotidianas, e onde se constitui a hegemonia como um sistema vivido - constituído e constituidor - de significados e valores, o senso de realidade. Lima argumenta que esse cenário não é uno, mas diversificado. As dimensões do conjunto de práticas e expectativas sobre a realidade apresentam cenários/espaços próprios, embora exista uma forte integração entre elas. Assim, há o cenário específico da política, da arte e assim por diante. Lima define o conceito de representação não apenas como um reflexo da realidade, mas também como sendo constituidora da mesma:

[...] os Cenários de Representação são, portanto, o espaço específico das diferentes representações da realidade, constituído e constituidor, lugar e objeto da articulação hegemônica total, construído em processos de longo prazo, na mídia e pela mídia (sobretudo na e pela televisão) (Lima, 2004, p. 14)

O conceito de CR-P é elaborado a partir de três pressupostos: a) a existência de uma sociedade media-centered; b) a existência da televisão como medium; e c) o exercício de uma hegemonia. Para que se tenha o exercício da hegemonia é preciso que a sociedade seja minimamente organizada e capaz de difundir ideologias, de modo a inviabilizar um Estado coercitivo. Parte-se de um processo democrático, em que ocorrem embates entre classes e facções pela direção, e em que os atores dominantes têm o consentimento da maioria da população.

Para a identificação do CR-P, concretamente, é preciso mapear os loci dos Elementos Constitutivos (EC) do Cenário de Representação dominante, delimitados pelos índices de audiência da programação, no caso da televisão (Lima, 2004). No Brasil, os elementos constitutivos devem ser identificados principalmente nas telenovelas e nos telejornais. No que se refere às novelas, Lima cita Guilhermoprieto (1993) para destacar a particularidade desse tipo de programa, que confunde ficção e realidade. Quanto aos telejornais, destaca-se a sua capacidade de omitir ou pautar informações durante a edição, ou seja, o seu poder de agenda.

O conceito de CR-P é amplo, e há uma série de outros aspectos que poderiam ser explorados. Todavia, a intenção aqui é abordar apenas os pontos que podem elucidar o caso analisado. Dessa forma, a proposta é finalizar a apresentação do conceito com base em dois aspectos muito importantes.

Para Lima (2004), existem elementos estruturais no imaginário social que constituem traços permanentes de nossa formação cultural. Associados a esses elementos persistentes, outros surgem de acordo com a conjuntura e, por isso, têm um caráter transitório. Assim, o autor propõe que em uma linha do tempo, o imaginário social, a cultura política e a hegemonia serão sempre anteriores aos Cenários de Representação, enquanto a conjuntura estará sempre à frente.

Por fim, o autor chama a atenção para o caráter desestabilizador ou de reforço que a conjuntura

\section{Figura 1}

\section{Posições Relativas dos Cenários de Representação}

\section{Tempo $>>$}

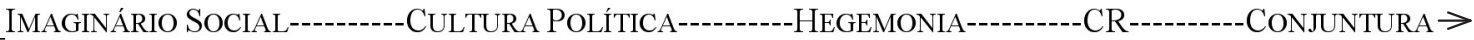


pode provocar no CR-P com o processo eleitoral. Argumenta "que esse impacto pode ocorrer sempre que os elementos conjunturais forem capazes de evocar elementos permanentes, pré-existentes no imaginário social e na cultura política" (Lima, 2004, p. 33).

Uma vez definido o conceito, cabe retomar o argumento central deste artigo, de que havia um cenário de representação favorável à campanha do SIM no momento precedente à veiculação da propaganda política.

Não é difícil constatar que vinha sendo construído um Cenário de Representação favorável à Frente Parlamentar por um Brasil sem Armas desde 2003, ocasião da implementação do Estatuto do Desarmamento. Desde aquele momento, segmentos da sociedade civil organizada e dos meios de comunicação - com grande participação de artistas - vinham se empenhando na campanha contra as armas. O sucesso da campanha de coleta de armas e as manifestações de apoio geraram uma predisposição política difusa à proibição das armas.

Telejornais e telenovelas, na qualidade de elementos constitutivos, apontavam para a formação desse cenário. Os telejornais da Rede Globo e das demais emissoras reiteradamente divulgavam imagens de tratores destruindo armas que haviam sido recolhidas por meio da devolução voluntária e cenas de caminhadas promovidas por ONGs com a participação de vários artistas globais - todos vestidos de branco - na orla da Zona Sul carioca, entre outras. Na novela Mulheres Apaixonadas, no ar na TV Globo em 2003, uma personagem, mãe de uma menina, morre no trânsito, vítima de uma bala perdida. Na semana posterior à veiculação da cena da morte da personagem, foi organizada uma caminhada pela paz na orla carioca. Os personagens da teledramaturgia participaram do evento, o que gerou uma gama de imagens para a novela. Ficção e realidade juntas na construção do cenário a favor do desarmamento.

Ao iniciar a veiculação da propaganda eleitoral, o empenho dos profissionais de marketing do SIM foi no sentido de vincular o referendo à campanha pelo desarmamento. No programa de abertura, a equipe do SIM propunha um Brasil sem armas e convocava as pessoas para votarem pela paz. A lógica da argumentação era: proibição da venda de armas, menos armas, menos mortes.
É certo que as duas últimas associações já despertavam grande consenso na audiência. Em síntese, o discurso central da campanha propunha que a vitória do SIM seria o desfecho natural de uma reação virtuosa que começara com a discussão do Estatuto do Desarmamento. As citações sobre o estatuto eram recorrentes nas propagandas: "considerado pela ONU uma das leis mais avançadas do mundo". E sobre os seus efeitos, "em 2004, pela primeira vez em treze anos, a morte por arma de fogo diminuiu em $8 \%$, mais de três mil vidas foram salvas".

Quinze milhões de armas estão nas mãos de civis. A gente é recordista mundial em mortes por armas de fogo. Em 2003, mais de 39 mil pessoas perderam vidas. 108 mortes por dia, quase cinco mortes por hora. E quase sempre, gente muito novinha (Regina Casé, no programa de abertura da campanha do SIM).

A verdade é uma só. Mais armas, mais crimes. Mais armas, mais mortes. Mais armas, mais feridos, paraplégicos, famílias destruídas. Mais armas, mais prejuízos para o sistema de saúde. Então por que apoiar as armas? O que as armas trazem de bom para o Brasil? Na verdade, nada. É preciso dizer basta e esse é o momento de começar. Se você tem dúvidas se seu voto vai ajudar, acredite: vai! Vamos dar o primeiro passo; chega de armas. Vote 2. Vote SIM (Programa do SIM, 18/10/2005).

Em suma, a Frente por um Brasil sem Armas utilizava os símbolos que marcaram a campanha do desarmamento, exibindo cenas referentes à destruição das armas e as caminhadas na orla, e também os argumentos, enfatizando valores já vastamente propagados em expressões como "pela vida", "menos armas, menos mortes".

Do ponto de vista prático, a vitória da Frente Parlamentar por um Brasil sem Armas parecia certa. Da perspectiva teórica também poderia se esperar tal resultado. Lima apresenta duas hipóteses sobre o ajuste de CR e propaganda em eleições:

1) O CR-P dominante, embora não prescreva os conteúdos da prática política, demarca os limites dentro dos quais as idéias e os conflitos políticos se desenrolam e são resolvidos, podendo neutralizar, modificar ou incorporar iniciativas opostas ou alternativas.

2) Um candidato em eleições nacionais e majoritárias dificilmente vencerá as eleições se a sua imagem pública não se ajustar ao CP-Dominante. 
Nesse caso, uma possível solução é a construção de um CR-P contra-hegemônico ou alternativo (2004, p. 30).

No entanto, a expectativa de vitória não se concretizou. A campanha da Frente por um Brasil sem Armas não obteve o sucesso esperado. Acreditamos que a campanha da Frente pelo Direito da Legitima Defesa impediu tal sucesso ao acessar valores que permeiam o imaginário social e que já estão enraizados em nossa cultura: a ameaça da quebra de direitos e a descrença no governo e nas instituições. Vale lembrar o pressuposto mencionado por Lima sobre a possibilidade de se desestruturar campanhas afinadas com o Cenário de Representação pela evocação de elementos permanentes, preexistentes no imaginário social e na cultura política. Assim, a Frente pela Legítima Defesa conseguiu reverter o cenário midiático francamente favorável à campanha do SIM.

Para entender como a campanha do NÃO obteve sucesso em sua estratégia, faz-se necessário analisar a propaganda negativa. Todavia, antes de dar esse novo passo, cabe ressaltar um último aspecto do conceito de Cenário de Representação. De acordo com Lima (2004), tal conceito está muito associado à noção de hegemonia, na qual está embutida a idéia de conflito na distribuição de poder e influência, havendo o dominado e o subordinado, a hegemonia e a contra-hegemonia, o cenário de representação dominante e o de representação alternativo. Partindo do princípio da existência do exercício da hegemonia na socieda-

Figura 2

Estratégias de Persuasão das Campanhas no Referendo

\section{Tempo $>>$}

IMAGINÁRIO SOCIAL---------CULTURA POLÍTICA

Campanha do NÃO evocava
-HEGEMONIA<smiles>C1CCC1</smiles>

Campanha do SIM evocava

Quadro 1

Atores, Preferências e Recursos*

\begin{tabular}{|c|c|c|}
\hline Atores & Preferências & Intensidades de preferências \\
\hline Poder Executivo 5 & \multirow{4}{*}{$\begin{array}{c}\text { A favor da proibição do comércio de } \\
\text { armas e munições }\end{array}$} & \multirow{4}{*}{ Alta } \\
\hline $\begin{array}{l}\text { ONGs/Igreja/Movimentos Sociais } \\
\text { (públicos atentos) }\end{array}$ & & \\
\hline Mídia $^{6}$ & & \\
\hline Frente do SIM & & \\
\hline Lobby da bala (públicos atentos) & \multirow{2}{*}{$\begin{array}{c}\text { Contra a proibição do comércio de } \\
\text { armas e munições }\end{array}$} & \multirow{2}{*}{ Alta } \\
\hline Frente do NÃO & & \\
\hline Deputados e senadores & Sucesso eleitoral & Alta \\
\hline Cidadãos & Variável & Variável \\
\hline
\end{tabular}

* O quadro original apresenta os recursos que cada ator possuía para a disputa, o que foi suprimido, já que não se trata de uma informação imprescindível para o presente estudo.

Fonte: Anastasia et al. (2006, p. 19). 
de, pressupõe-se a possibilidade de disputas internas (intra-hegemônicas) e/ou externas (contrahegemônicas).

Anastásia, Inácio e Novais (2006) elaboraram um quadro que descrevia os atores na disputa pelo referendo e como eram suas inserções (Quadro 1). A identificação da composição de forças a favor da campanha do SIM reforça a idéia de que, no momento antecedente à propaganda eleitoral, eles contavam com um grupo hegemônico e com um Cenário de Representação também hegemônico, ainda que seja desconfortável, na perspectiva do senso comum, a idéia de classificar o que os autores chamaram de "lobby da bala" como contrahegemônico.

\section{A propaganda negativa}

A propaganda política é classificada como negativa quando tenta crescer, levar vantagem, referindo-se a aspectos negativos de seu oponente - seja o adversário uma pessoa, seja uma política mais do que enfatizando seus atributos positivos. O assunto é polêmico e vem ganhando cada vez mais espaço na literatura internacional.

A principal questão que se coloca é sobre a eficiência desse tipo de propaganda, particularmente em relação à capacidade de mobilizar e de persuadir. McGuire (1973), ainda nos anos de 1970, sugeriu que o uso de apelos negativos, como preocupação e medo, pode aumentar a motivação das pessoas no sentido de aceitarem os argumentos das campanhas e aderirem a um candidato. Isso ocorreria porque o medo energiza e guia $\mathrm{o}$ organismo, levando as pessoas a adotar comportamentos do tipo "voar ou voar", uma referência de McGuire ao que ele imagina que os pássaros experimentam quando se deparam com a necessidade de voar pela primeira vez. No entanto, de acordo com o autor, é prudente usar a estratégia com cautela, pois qualquer excesso pode gerar efeito contrário. Nesse caso, a ansiedade exagerada pode levar o receptor a se desinteressar pela mensagem e o assunto.

Para Gina Garramone (1984), o efeito bumerangue é o resultado mais recorrente quando se utiliza a propaganda negativa. Em seu artigo, "Voter response to negative political ads", ela aponta que o efeito da propaganda varia de acordo com a percepção de sua veracidade. Uma vez que a mensagem é tida como verossímil, ela ganha o interesse da audiência, e o adversário - alvo do ataque passa a ser desqualificado. No entanto, se o ataque for visto como não verdadeiro e não documentado, o emissor sofre o revés, causando o efeito bumerangue.

Mais recentemente, Ansolabehere e Iyengar (1995) argumentaram que a propaganda negativa tende a reforçar a decisão do voto entre os eleitores partidários e a desmobilizar o eleitor independente para o pleito. De acordo com os autores, isso acontece porque os eleitores não partidários tendem a prestar muita atenção nas mensagens divulgadas pela propaganda negativa, que em última instância reforçam a desilusão entre esses eleitores, desestimulando a participarem do processo.

Nos pleitos norte-americanos, esse tipo de propaganda faz diminuir a disposição para o voto em 5\% dos eleitores, criando, pois, um desmobilizador acompanhado de uma sensação de ineficácia política (Ansolabehere e Iyengar, 1995). Vreese e Semetko (2002), ao avaliarem o efeito da cobertura da imprensa no eleitorado na ocasião do referendo sobre a adoção do Euro na Dinamarca, em 2000, também constataram que eleitores com diferentes níveis de envolvimento e conhecimento políticos reagem diferentemente às mensagens negativas. Elas seriam eficientes para mobilizar certo segmento do eleitorado (mais envolvido) e para desmobilizar outro (não envolvido).

A campanha do NÃO no Brasil centrou sua atenção nos temas "direito do cidadão", "criminalidade" e "desempenho do Estado". O argumento central era de que a proibição do comércio de armas tiraria dos brasileiros o direito de adquirir e portar uma arma sem que o Estado garantisse a sua segurança. Buscou enfaticamente separar a campanha pelo Estatuto do Desarmamento do pleito do referendo. Enfatizou que a proibição da venda de armas não levaria ao desarmamento do ladrão, mas apenas da sociedade civil. A Frente pela Legítima Defesa solicitou às pessoas que se imaginassem numa sociedade totalmente desarmada e dependente de um sistema de segurança pública ineficiente e fracassado.

Ao apontar para a ineficiência do Estado, a campanha ressaltava a vulnerabilidade do cidadão caso a proibição do comércio de armas e munição 
se efetivasse. O resultado final foi a polarização das campanhas e a queda da motivação para o voto, como será visto posteriormente.

Até esse momento, foram expostas as principais linhas de argumentação apresentadas pelas duas frentes em disputa. A seguir, o objetivo é mostrar como tais discursos foram apresentados nos programas.

\section{O embate de argumentos no horário eleitoral}

Robert Merton (1968) foi o primeiro sociólogo a elaborar uma metodologia para a análise do efeito da mídia na opinião pública. Ele propunha o uso de duas técnicas para verificar o efeito da divulgação de uma propaganda na audiência: a primeira seria uma análise de conteúdo da mensagem, e a segunda, uma análise de recepção, com entrevistas em profundidade individual ou em grupo. Este trabalho segue tal metodologia.

Assim, nesta etapa, o objetivo é dar continuidade à análise de conteúdo dos programas do Horário Eleitoral. A intenção é detalhar a estratégia de retórica das campanhas, detendo-se nos temas, nos tipos de apelo e nos oradores utilizados. A unidade de análise utilizada na avaliação é o segmento, isto é, cada parte do programa em que o assunto ou a imagem permanece o mesmo. Isso quer dizer que diante de qualquer mudança de imagem ou de assunto é contado um novo segmento.

\section{Frente Parlamentar por um}

Brasil sem Armas

A partir da análise de conteúdo, particularmente da mensuração da abordagem dos temas, foi possível verificar que a estratégia inicial da campanha do SIM foi elaborada de modo a combinar com o Cenário de Representação resultante da mobilização pelo Estatuto do Desarmamento. Para isso, abordou-se o tema "arma e violência", cujo lema principal era "mais armas, mais mortes", como já mencionado anteriormente (Tabela 1).

Nesse aspecto, o discurso esteve muito voltado para os "acidentes com armas" e a "crimina- lidade", o que dava à campanha um tom emocional e de proximidade, sobretudo quando se tratava de depoimentos que expunham momentos dolorosos e sofridos.

No entanto, no decorrer da veiculação dos programas, o mote inicial precisou ser adaptado ao discurso da campanha adversária, e a campanha do SIM passou a abordar o tema "a arma e a discussão da venda baseada em valores". Nesse contexto, a discussão em torno do "direito" consistia numa clara resposta à ofensiva do adversário, o qual insistia que a campanha do SIM pretendia retirar um direito do cidadão. O argumento de defesa constava em repetir que o direito à vida estaria mais assegurado com menos armas na sociedade. De acordo com Figueiredo et. al. (2000), em uma disputa eleitoral, quando uma campanha consegue pautar a outra, suas chances de vitória aumentam consideravelmente. Para Anastasia et. al. (2006), uma vez introduzida a dimensão dos "direitos" pelos que apoiavam a campanha do NÃO, só restou aos defensores do SIM a capitulação aos termos de campanha propostos por seus oponentes.

Ao analisarmos quantitativamente a distribuição dos fragmentos, verificou-se que a Frente por um Brasil Sem Armas investiu ainda muito tempo na propaganda que tem como objetivo a divulgação da própria campanha, denominada "metacampanha". Buscou-se mostrar imagens de uma campanha festiva e forte, cuja comprovação costuma estar na exposição de resultados de pesquisa de intenção de votos favorável. Foram veiculadas ainda instruções sobre como votar. Essa parte do programa foi importante porque possibilitou criar um clima de vitória, sempre muito oportuno em disputas. Como já vimos, entre as teorias da comunicação que tratam do efeito das campanhas no ambiente informacional há a teoria da espiral do silêncio (Noelle-Neuman, 1993), segundo a qual os eleitores, quando percebem que estão apoiando o lado vitorioso da disputa, tendem a expor mais suas atitudes e argumentos, ao passo que os que sentem estar no lado mais fraco tendem a silenciar. Esse processo de abstenção da fala de seu eleitorado é devastador para uma campanha. Por isso, na tentativa de evitar tal fenômeno, os publicitários investiram muito na "metacampanha". O objetivo era manter a alegria e a sensação de conquista da campanha do desarmamento. 
O discurso emocional foi o mais freqüente na campanha do SIM (Tabela 2). Há que se constatar, no entanto, que ao longo da campanha o apelo pragmático também foi aos poucos sendo adotado. Se no início predominavam os depoimentos de artistas globais e de pessoas comuns, no final, começaram a aparecer na tela, de maneira freqüente, especialistas da área (Tabela 3). Suas falas foram utilizadas para intercalar depoimentos pessoais sobre tristes experiências de vida, misturando autoridade técnica e sensibilidade. A seguir, um segmento exemplar do programa do SIM:
Locutor em off: Arma fere. Vinte mil brasileiros chegam aos hospitais com ferimento devido à bala. Elifran Mesquita (vítima em um leito de hospital): Isso aqui foi um tiro de uma arma de fogo. Isso não pode acontecer, gente.

Locutor em off: Arma aleija. Cinqüenta mil brasileiros vão passar o resto de suas vidas em cadeiras de rodas.

Dr. Paulo Carneiro (diretor de hospital em Minas Gerais): É um indivíduo que muitas vezes vai ficar incapacitado e vai viver à custa do Estado.

Locutor em off: Arma mata. Armas matam 36 mil brasileiros por ano.

Figura 3

Estratégias de Persuasão proposta pela Frente Parlamentar por um Brasil sem Armas

\section{Tempo $>>$}

IMAGINÁRIO SOCIAL---------CULTURA POLÍTICA -HEGEMONIA-CR-------CONJUNTURA $\rightarrow$

$\Uparrow$

Arma e violência

Metacampanha $(58,5 \%)$

Tabela 1

Tema Predominante ( $\%$ de fragmentos)

\begin{tabular}{|l|l|}
\hline Campanha do SIM \\
\hline Arma e violência \\
\hline Violência entre conhecidos & 2,2 \\
\hline Violência entre desconhecidos & 9,6 \\
\hline Criminalidade & 12 \\
\hline Acidentes com armas & 13,2 \\
\hline Suicídios & 0,2 \\
\hline Arma e a conta para o Estado \\
\hline Gastos públicos com a saúde & 2,5 \\
\hline Gastos públicos com a segurança & 0,5 \\
\hline Arma e a discussão da venda baseada em valores \\
\hline Direito & 16,3 \\
\hline Estado & 9,6 \\
\hline Liberdade & 8,2 \\
\hline Democracia & 4,4 \\
\hline Metacampanha & 21,2 \\
\hline Total & 100 \\
\hline &
\end{tabular}

Tabela 2

Apelo Predominante (\% de fragmentos)

\begin{tabular}{|l|l|}
\hline Campanha SIM & 33 \\
\hline Pragmático & 26 \\
\hline Ideológico, político e jurídico & 35 \\
\hline Emocional & 6 \\
\hline Documental & 100 \\
\hline Total &
\end{tabular}

Tabela 3

Orador Dominante (\% de fragmentos)

\begin{tabular}{|l|l|}
\hline Campanha do SIM & \multicolumn{2}{l|}{} \\
\hline Garoto Propaganda & 10,2 \\
\hline Integrante da frente parlamentar & 1,3 \\
\hline Off locator & 35 \\
\hline Off cantor & 5,2 \\
\hline Popular & 20,8 \\
\hline Personalidade & 14,8 \\
\hline Especialista & 11,8 \\
\hline Instrumental & 0,9 \\
\hline Total & 100 \\
\hline
\end{tabular}


Gláucio Ary Soares (pesquisador do Iuperj): Não vemos a tragédia que está acontecendo. Uma tragédia que atinge predominantemente as pessoas mais pobres.

Valdete da Silva, chorando ao lado do filho hospitalizado: Meu filho é uma criança. Meu filho tem só 17 anos. Não viveu ainda.

Locutor em off: Arma destrói o futuro.

Cel. José Vicente da Silva Jr: Nos últimos dez anos, só no estado de São Paulo, foram quase 150 mil armas que desapareceram. Armas legais, compradas em lojas, que sumiram das mãos de seu proprietário e foram parar nas mãos dos bandidos.

Marina Magessi (inspetora da Polícia Civil do Rio de Janeiro): Bandido não compra arma, mas rouba ou furta de quem compra de maneira legal. Dalmo de Abreu Dallari (jurista): A arma de fogo não dá vida a ninguém, ela dá a morte. Ela não é instrumento de vida. Ela não é instrumento de paz. Ela é um instrumento de ferimento, instrumento de morte e tragédia (Programa do SIM, 18/10/2005).

\section{Frente Parlamentar pelo Direito}

da Legítima Defesa

Mais de $50 \%$ dos segmentos da campanha do NÃO detiveram-se no tema "arma e discussão da venda baseada em valores", evidenciando a possibilidade da perda do direito e da vulnerabilidade do cidadão diante de um Estado ineficiente (Figura 4, Tabela 4). Esta estratégia já exaustivamente analisada, pode agora ser mensurada.

Ao longo de toda a campanha, as críticas à ineficiência governamental foram inseridas de maneira direta, mas também de um jeito quase despretensioso. A seguir, alguns exemplos do uso da propaganda negativa a partir de valores presentes na crença dos brasileiros:
Alberto Fraga (presidente da Frente Parlamentar pelo Direito da Legítima Defesa): O Governo Federal, não conseguindo desarmar os bandidos, tenta agora, através do seu voto, desarmar os cidadãos. Está começando uma campanha que tem como marco o compromisso com a verdade. Estamos aqui para defender o direito das vitimas da violência: os cidadãos de bem. Gente que o governo não consegue proteger e ainda assim pretende desarmar (Programa do NÃO, 6/10/2005).

Jornalista/âncora: O Governo Federal deveria fazer a sua parte, mas não faz. Nos últimos anos, o dinheiro da segurança só diminuiu e o resultado todo mundo vê: a polícia não consegue vencer os bandidos porque falta tudo (Programa do NÃO, 6/10/2005).

Mara Assaf (mãe): Hoje estou tentando dar voz ao meu filho, que me foi tirado. Atrás da arma que matou o meu filho tinha um assassino, produto do desgoverno. Que tipo de vida eles estão defendendo? Uma vida em que a população vive ameaçada atrás das grades? (Programa do NÃO, 6/10/2005).

Repórter: Esta pesquisa do SUS diz que 39 mil pessoas morrem por arma de fogo. Em primeiro lugar, é estranho que a pesquisa tenha sido realizada pelo SUS, que deveria estar cuidando da saúde da população. Mas, vamos lá... (Programa do NÃO, 4/10/2005).

Constata-se ainda que a campanha do NÃO praticamente não abordou o tema-chave do oponente: "acidentes com armas".

De acordo com que as pesquisas de intenção de voto indicavam, mostrando os resultados positivos da campanha da Frente pela Legítima Defesa, o dispositivo de "metacampanha" passou a ser também recorrentemente utilizado neste caso para divulgar a mudança de atitude do eleitorado:

\section{Figura 4}

\section{Estratégias de Persuasão da Frente Parlamentar pelo Direito da Legítima Defesa}

\section{Tempo $>>$}

IMAGINÁRIO SOCIAL---------CULTURA PoLíTICA----------HEGEMONIA------------CR-------CONJUNTURA $\rightarrow$

Arma e discussão da venda baseada em valores 
Fumiyo Kurisaki (presidente do Movimento das Vítimas de Violência pela Justiça e Paz): Olha, antes eu pensava em votar SIM, porque eu realmente acreditava que aconteceria, que fosse haver o desarmamento pelo lado dos bandidos. Mas hoje eu vou votar NÃO, porque eu vejo que os bandidos vão se armar mais ainda do que hoje. Eles realmente não compram as armas legais.

Locutor em off: A proibição não resolve problema nenhum. Só tira um direito do cidadão. Defenda sua liberdade. Contra a proibição vote NÃO (Programa do NÃO, 19/10/2005).

Paulo Pereira da Silva (presidente da Força Sindical): Sempre fui a favor do desarmamento. Portanto, sempre fui a favor do SIM. Depois de ouvir os argumentos pró e contra, hoje estou convencido de que temos que votar NÃO, dia 23. Por quê?

Tabela 4

\section{Tema Predominante ( $\%$ de fragmentos)}

\begin{tabular}{|c|c|}
\hline \multicolumn{2}{|l|}{ Campanha do NÃO } \\
\hline \multicolumn{2}{|l|}{ Arma e violência } \\
\hline Violência entre conhecidos & 0,2 \\
\hline Violência entre desconhecidos & 7,1 \\
\hline Criminalidade & 12,1 \\
\hline Acidentes com armas & 3,2 \\
\hline Suicídios & 0 \\
\hline \multicolumn{2}{|l|}{ Arma e a conta para o Estado } \\
\hline Gastos públicos com a saúde & 0,2 \\
\hline Gastos públicos com a segurança & 0,6 \\
\hline \multicolumn{2}{|c|}{ Arma e a discussão da venda baseada em valores } \\
\hline Direito & 36,8 \\
\hline Estado & 11,9 \\
\hline Liberdade & 2,2 \\
\hline Democracia & 4,0 \\
\hline Metacampanha & 23 \\
\hline Total & 100 \\
\hline
\end{tabular}

Tabela 5

Apelo Predominante ( $\%$ de fragmentos)

\begin{tabular}{|l|l|}
\hline \multicolumn{2}{|l|}{ Campanha do NÃO } \\
\hline Pragmático & 36,6 \\
\hline Ideológico, político e jurídico & 37,1 \\
\hline Emocional & 19,8 \\
\hline Documental & 6,5 \\
\hline Total & 100 \\
\hline
\end{tabular}

Porque o que eles querem é desarmar as pessoas de bem e não os bandidos. Não desarmando os bandidos, depois do dia 23, o bandido terá certeza de que você não tem arma em casa. Ele vai invadir sua casa, estuprar sua mulher, seu filho e você não vai poder fazer nada. Portanto, dia 23 , vote 1 , vote NÃO.(Programa do NÃO, 16/10/2005).

A análise quantitativa da distribuição dos segmentos permite verificar a prevalência dos apelos "ideológico/político/jurídico" e "pragmático" em oposição à postura da campanha adversária, prioritariamente emocional.

O formato predominante da campanha foi do telejornal, reafirmando o seu caráter racional e pragmático. A campanha utilizou uma jornalista como âncora, que acabou desempenhando o papel de oradora predominante (Tabela 6). Desde a sua apresentação, no início da propaganda, a jornalista tentou passar uma atitude de imparcialidade, parecia disposta apenas a mostrar a verdade para que o eleitor pudesse decidir o seu voto e não se arrepender depois. Ou seja, tratava-se de um trabalho de utilidade pública e não de uma garota propaganda ávida pelo voto:

Jornalista/âncora: Olá, eu sou Carmen Cestari, sou jornalista, e a partir de hoje vou conversar com vocês sobre a votação que acontecerá daqui três semanas, dia 23. Vamos responder com o nosso voto à seguinte pergunta: "O comércio de armas de fogo e munição deve ser proibido no Brasil?" A pergunta é essa, sobre o comércio ou

Tabela 6

\section{Orador Dominante (\% de fragmentos)}

\begin{tabular}{|l|l|}
\hline Campanha do NÃO & 6,7 \\
\hline Garoto Propaganda & 33,7 \\
\hline Âncora & 2,3 \\
\hline Integrante da frente parlamentar & 29,3 \\
\hline Off locator & 1,9 \\
\hline Off cantor & 13,5 \\
\hline Popular & 1,9 \\
\hline Personagem de ficção & 0,8 \\
\hline Personalidade & 8,8 \\
\hline Especialista & 1,1 \\
\hline Instrumental & 100 \\
\hline Total & \\
\hline
\end{tabular}


não legal de armas.Tem gente querendo confundir falando em desarmamento. Eles não fazem o desarmamento dos bandidos e também não vão proibir o comércio ilegal de armas que é onde os bandidos compram. Então a gente tem que ter cuidado com o que a gente vai ouvir por aí. O que a gente quer é que você esteja bem informado para tomar a decisão pensada, que não o prejudique no futuro. Mais do que uma proibição, o que está em jogo é a perda de um direito seu. É não abrir mão de sua liberdade (Programa do NÃO, primeiro dia de veiculação).

Os parlamentares estiveram muito pouco presentes nos programas políticos das duas campanhas e também na cobertura da imprensa. Fuks e Novais (2006), ao analisarem a cobertura do evento pelos jornais Folha de São Paulo e O Globo, concluíram que a leitura da imprensa pouco informou a respeito das atitudes de deputados, senadores e outras lideranças. Quando Araújo e Santana (2006) avaliaram o desempenho dos parlamentares de maneira mais geral em relação ao referendo, propuseram que o percentual de engajamento na disputa política refletia a estratégia de desresponsabilização em relação aos resultados do embate. A sugestão aqui é de que a reduzida participação na mídia de modo geral seja também conseqüência de tal estratégia.

\section{A revoada de intenções de voto: o comportamento do eleitor}

Para o estudo da recepção foram realizadas entrevistas em profundidade com 21 eleitores de Curitiba. Na definição do perfil dos entrevistados, foram consideradas as variáveis idade, classe social, sexo e postura em relação ao pleito. adotouse a técnica bola de neve, constante em estudos qualitativos, para o trabalho de recrutamento. De acordo com essa técnica, cria-se uma rede na qual as pessoas envolvidas no projeto de pesquisa entram em contato com seus conhecidos para que esses convidem, por sua vez, amigos para participar das entrevistas (Geenbaun, 1998).

Os integrantes do Núcleo de Estudos de Comunicação Política da Universidade Federal do Paraná distribuíram 112 questionários/convites para a participação da pesquisa entre amigos, familiares e conhecidos, os quais o repassaram adiante.
Os papéis eram preenchidos e então devolvidos. Vinte e quatro pessoas deram um retorno positivo, aceitando participar da pesquisa. A taxa de retorno foi muito semelhante àquela encontrada em outros estudos. Logo na primeira rodada de entrevistas, três pessoas voltaram atrás e declinaram do convite, desistindo de participar da pesquisa. A amostra ficou com 21 entrevistados (Quadro 2). Os selecionados eram, portanto, conhecidos de conhecidos, mas desconhecidos das pesquisadoras.

Não houve a intenção de elaborar uma amostra representativa, já que esse não é o objetivo da entrevista qualitativa. Houve, sim, a preocupação de identificar opiniões e argumentos originados de diferentes perfis de eleitores. Participaram das entrevistas pessoas de diferentes classes sociais e idades e com atitudes do voto distintas.

Ainda que a pesquisa qualitativa não demande uma amostra representativa da população, causa estranheza quando esta destoa muito do universo populacional. A princípio, esse não é o caso deste trabalho. Na Tabela 2, é possível perceber que não há grandes discrepâncias entre a amostra e o universo no que se refere às distribuições por idade e sexo. Em relação à distribuição por classe social, cabe destacar que o grupo de classe A/B1 está sobre-representado. Fazendo uma comparação entre a distribuição por classe social na amostra e a realidade da região metropolitana de Curitiba, na qual esta pesquisa foi desenvolvida, é possível identificar os seguintes números: classe A/B1 (33\% na amostra por 19\% no universo), classe B2/C (48\% por $61 \%$ ) e classe $\mathrm{D} / \mathrm{E}(19 \%$ por 20\%).? Percebe-se que a maior discrepância entre amostra e universo acontece em torno de 14 pontos, o que certamente não compromete uma amostra que não tem o compromisso de ser representativa em termos estatísticos.

Foram feitas três entrevistas com cada um dos participantes: a primeira, em agosto, antes da veiculação do Horário Eleitoral, a segunda, entre os dias 1 e 15 de outubro, durante a veiculação da propaganda política, e a última, no momento posterior à veiculação da propaganda, mas antes da votação do referendo. Os encontros aconteciam nas casas dos entrevistados ou no trabalho, na hora de almoço, e tinham a duração média de $45 \mathrm{~min}$. A conversa seguia um roteiro semi-estruturado e eram abordados temas como sensação 
de segurança e/ou preocupação com a violência no cotidiano, avaliação do desempenho do Estado na área, avaliação da importância e da motivação para o referendo, razões para a decisão do voto, recall das mensagens de campanhas e o processamento dos diferentes argumentos veiculados no Horário Eleitoral.

A seguir, será apresentada uma discussão sobre o efeito das propagandas no grau de motivação dos eleitores e, posteriormente, será analisado o efeito da persuasão, propriamente dito.

\section{Motivação}

Os entrevistados se dividiam entre aqueles que viam importância na realização do referendo, e estavam motivados, e aqueles que não o consideravam importante e, portanto, não estavam animados para a consulta. Registra-se, desde já, que o índice de motivação entre os eleitores foi sendo reduzido ao longo da campanha de televisão.

Os entrevistados que viam importância e estavam motivados para o referendo demonstraram ter uma atitude política marcada pelo engajamen- to, com grande apego à possibilidade de participação e intervenção nas questões públicas.

É importante que haja mobilização da sociedade (Homem, classe B/C, 18 a 29 anos, pelo SIM).

Assim o povo pode dizer o que pensa e tem o direito de dar a sua opinião (Mulher, classe $\mathrm{D}$, mais de 50 anos, indecisa e depois pelo NÃO).

É importante participarmos de tudo que se refere à nossa segurança (Mulher, classe $\mathrm{A} / \mathrm{B}, 30$ a 50 anos, pelo SIM).

É a oportunidade de despertar a consciência coletiva para o desarmamento (Homem, classe B/C, 30 a 50 anos, pelo SIM).

A participação de todos implica em poder influenciar o resultado (Homem, classe $\mathrm{A} / \mathrm{B}$, mais de 50 anos, pelo NÃO).

Já entre aqueles que não consideravam importante a consulta popular sobre o desarmamento foi possível identificar os seguintes motivos para a sua atitude:

(1) Comportamento associado ao conceito de impotência política. Ou seja, tem-se um eleitor que não está acostumado a participar e afetar as decisões do processo político e, por isso, acredita que nada está sujeito à sua influência. Daí, o referendo causar estranheza nesse segmento, acostumado com o processo de delegação dos assuntos

Quadro 2

Perfil dos entrevistados

\begin{tabular}{|c|c|c|c|}
\hline \multirow{2}{*}{ Idade } & \multicolumn{3}{|l|}{ Classe Social } \\
\hline & $\mathbf{A} / \mathbf{B} 1$ & B2/C & D \\
\hline \multirow{3}{*}{18 a 29} & \multirow{3}{*}{ Homem/Indeciso } & Mulher/Indecisa & \multirow{3}{*}{ Mulher/NÃO } \\
\hline & & $\begin{array}{l}\text { Mulher/SIM } \\
\text { Homem/SIM }\end{array}$ & \\
\hline & & Homem/NÃO & \\
\hline \multirow{4}{*}{30 a 50} & \multirow{2}{*}{ Mulher/SIM } & Mulher/Indecisa & \multirow{4}{*}{ Homem/SIM } \\
\hline & & & \\
\hline & \multirow{2}{*}{$\begin{array}{l}\text { Mulher/NÃO } \\
\text { Mulher/NÃO }\end{array}$} & & \\
\hline & & $\begin{array}{l}\text { Mulher/NÃO } \\
\text { Homem/NÃO }\end{array}$ & \\
\hline \multirow{2}{*}{$\begin{array}{l}\text { Mais de } \\
50\end{array}$} & Mulher/SIM & \multirow{2}{*}{$\begin{array}{l}\text { Homem/NÃO } \\
\text { Homem/NÃO }\end{array}$} & Mulher/Indecisa \\
\hline & $\begin{array}{l}\text { Homem/NÃO } \\
\text { Homem/NÃO }\end{array}$ & & Mulher/NÃO \\
\hline
\end{tabular}


mais gerais e inclusive daqueles que seriam mais importantes ou os mobilizariam mais para a participação.

As autoridades que deveriam fazer as leis cabíveis neste caso, já que todas são feitas por eles e são eles que elaboram e não pedem a nossa opinião para outros casos como, por exemplo, o aumento do próprio salário e punição dos colegas deputados. Já que é assim, que fique tudo com eles (Homem, classe $\mathrm{B} / \mathrm{C}$, mais de 50 anos, pelo NÃO).

(2) A descrença no governo e nas demais instituições políticas também leva à falta de mobilização. Para os eleitores, o governo não estava assumindo a sua responsabilidade de prover a segurança, o que deveria ser sua principal preocupação, devendo resolvê-la antes de propor qualquer alteração na lei.

As duas motivações para a falta de mobilização estão fortemente relacionadas com a leitura negativa em relação à política.

O governo deveria estar preocupado em tirar as armas dos bandidos ao invés de ficar promovendo referendo. Se ele cuidasse da segurança, não seria preciso nem mesmo esse referendo. Ou seja, a solução não é o referendo, que é uma perda de tempo e dinheiro (Mulher, classe B/C, 30 a 50 anos, indecisa, depois pelo NÃO).

Esse tipo de argumento foi paulatinamente sendo mais utilizado pelos entrevistados e certamente em resposta à estratégia da campanha do NÃO, que o reforçava. É importante chamar a atenção para como a propaganda negativa da Frente pelo Direito à Legítima Defesa paradoxalmente conduzia à desmotivação em relação ao pleito - ao desânimo, à desilusão - e era capaz de angariar votos.

Vale ressaltar a constatação de que a propaganda do NÃO - a partir de uma pauta extremamente negativa - serviu mais para desiludir do que para motivar os eleitores. Mediante a pesquisa qualitativa foi possível identificar por que o eleitor, mesmo desanimado, adotou uma atitude em relação ao pleito. Preocupado com a situação da segurança e ao mesmo tempo sem esperança de que o quadro mudasse para melhor com o resultado do referendo, ele escolheu a opção menos pior, sem qualquer entusiasmo por fazê-lo. A paixão que o conduzia não era positiva, mas negativa.

Gláucio Ary Soares em artigo elaborado a partir do resultado de pesquisas tracking realizadas pela campanha do SIM faz uma análise da intenção de voto dos eleitores e da estrutura atitudinal que a sustentava. Em relação à motivação para o pleito, o autor identificou no momento da realização da pesquisa uma tendência ao crescimento de respostas que denotavam falta de interesse. O número de respostas nesse sentido - "O referendo é pouco ou nada importante", "não sei" e "sem resposta" - subiu de aproximadamente um terço a cerca da metade dos entrevistados entre os dias 1 e 12 de outubro. De acordo com o sociólogo, "a queda do SIM ocorreu pari passu com o decréscimo do interesse pelo referendo" (Soares, 2006, p. 70).

A partir dos dados qualitativos e quantitativos, é possível sintetizar que no momento em que a campanha do referendo se desligou da campanha do desarmamento, estratégia comandada pela Frente pelo Direito à Legítima Defesa, ocorreu também a redução da esperança de um Brasil melhor sem armas entre os eleitores e, conseqüentemente, o aumento da desilusão.

Em detalhe, os dados apresentados por Soares mostram que ao longo dos doze dias em que a intenção de voto no NÃO cresceu de 33\% para $50 \%$ e a intenção de voto no SIM reduziu de 59\% para $42 \%$, o número de pessoas que diziam achar o referendo "pouco ou nada importante" mais os que não sabiam ou não tinham opinião sobre a importância da votação cresceu de aproximadamente $32 \%$ para $47 \%$. Soares insiste: "Parto do princípio de que a vinculação entre a argumentação 'primária' do SIM era a vida e de que existe uma correlação entre a sua importância e o interesse pelo referendo" (Idem, p. 80).

(3) Já um terceiro segmento de eleitores demonstrava desinteresse pela consulta popular sem que tal atitude fosse motivada por qualquer postura política. Nesse caso, havia a percepção de que o referendo não era importante porque o problema em questão era incapaz de alterar o seu cotidiano. Tratava-se, pois, da alienação no sentido corriqueiro do termo, ou seja, indiferença.

Se não tivesse o referendo, não mudaria nossas vi- 
das (Mulher, classe B/C, 30 a 50 anos, pelo Não). A proibição ou comercialização de armas é indiferente (Homem, classe B/C, 18 a 20, pelo NÃO).

(4) Por fim, para parte dos eleitores, o referendo era uma invenção para tirar atenção das denúncias de corrupção - "mensalão" - que estavam surgindo em Brasília.

\section{Persuasão}

Em uma disputa as campanhas buscam reforçar a atitude de seus eleitores; oferecer subsídios argumentos - para que o eleitor indeciso se defina pela campanha e não, pelos adversários; e o mais difícil, reverter os votos dos adversários. A seguir, busca-se identificar como as duas frentes buscaram com seus programas alcançar tais objetivos.

\section{(a) Frente Parlamentar por um Brasil Sem Ar- mas}

Os eleitores que começaram e terminaram pelo SIM tiveram sua opinião reforçada pelo discurso emocional e de proximidade da campanha. Os principais argumentos apresentados pelos entrevistados para continuarem votando no SIM eram: a possibilidade de redução dos acidentes com armas e os decorrentes da violência entre conhecidos. Eles apostavam na diminuição das mortes com o fim da comercialização. Em síntese, acreditavam no lema: "menos armas, menos mortes":

[O Horário Eleitoral] trouxe informações que eu não sabia. Como, por exemplo, o grande número de acidentes que acontece com armas de fogo (Mulher, classe A/B, 30 a 50 anos, pelo SIM).

[O Horário Eleitoral] mostrou que muitas pessoas têm armas e não sabem guardar, então acontecem muitos acidentes. Mostrou também que acontecem muitas e muitas mortes de inocentes com balas perdidas e mortes por vingança principalmente entre vizinhos (Mulher, classe B/C, 30 a 50 anos, pelo SIM).

Soares (2006), ao elaborar a correlação entre argumentos e certeza do voto por nível educacional, evidencia o peso do apelo central da campanha do SIM na definição do voto. A atitude positiva em relação ao mote "Votar pela proibição do comércio de armas de fogo é votar pela vida" e a certeza do voto no SIM apresentaram um dos maiores índices de correlação. ${ }^{8} \mathrm{~A}$ aceitação do argumento "ter uma arma de fogo não é sinônimo de segurança, é sinônimo de tragédia" também demonstrou grande correlação com a certeza do voto no SIM, particularmente entre os eleitores com mais escolaridade.

Assim como aconteceu no processo de reforço para o voto no SIM, o argumento "menos armas, mais vidas" - baseado em informações sobre acidentes domésticos com armas e entre conhecidos - motivou a decisão pelo voto na Frente pelo Brasil sem Armas entre um indeciso e uma eleitora que inicialmente era a favor do NÃO. Ou seja, os dados qualitativos e quantitativos demonstram que os eleitores que votaram pelo SIM estavam afinados com o discurso que relacionava "arma e violência", presente desde o início da disputa no Cenário de Representação Política e reforçado com veemência ao longo da campanha da Frente por

\section{Figura 5}

Efeito da Persuasão da Retórica da Frente Parlamentar por um Brasil sem Armas

\section{Tempo $>>$}

IMAGINÁRIO SOCIAL---------CULTURA POLÍTICA -HEGEMONIACRCONJUNTURA $\rightarrow$

A arma e a violência

Meta campanha $(58,5 \%)$ 
um Brasil sem Armas.

\section{(b) Frente Parlamentar pelo Direito da Legítima Defesa}

Os eleitores que começaram e terminaram a favor do NÃO e que decidiram por tal opção ao longo da veiculação do Horário Eleitoral avaliaram a propaganda da Frente pelo Direito à Legítima
Defesa como muito informativa. Entre as mensagens veiculadas, as consideradas mais importantes para a confirmação ou a escolha do voto foram: "a proibição tira um direito adquirido" e "a inoperância do Estado na área de segurança”.

Os entrevistados que votaram NÃO entenderam, a partir da propaganda, que a proibição da venda das armas não levaria ao desarmamento. Por isso, votar SIM não significava o desarmamen-

Quadro 3

Recepção da Mensagem

\begin{tabular}{|c|c|c|c|}
\hline \multicolumn{2}{|c|}{$\begin{array}{l}\text { Recepção do Horário Eleitoral e } \\
\text { efeito da persuasão }\end{array}$} & $\begin{array}{l}\text { Avaliação e recall dos programas: } \\
\text { Frente Parlamentar Por um Brasil } \\
\text { sem Armas }\end{array}$ & $\begin{array}{l}\text { Avaliação e recall dos programas: } \\
\text { Frente Parlamentar pela Legítima } \\
\text { Defesa }\end{array}$ \\
\hline \multirow[b]{2}{*}{ REFORÇO } & $\begin{array}{l}\text { Eleitor que } \\
\text { começou e termi- } \\
\text { nou pelo SIM }\end{array}$ & $\begin{array}{l}\text { - Mais franca. } \\
\text { - Mais humana. } \\
\text { - Mais coerente. }\end{array}$ & $\begin{array}{l}\text { - Muito polêmica, confusa e com } \\
\text { argumentos falhos. } \\
\text { - Mais preocupada em atacar o gov- } \\
\text { erno do que em apresentar as razões } \\
\text { para o voto. }\end{array}$ \\
\hline & $\begin{array}{l}\text { Eleitor que } \\
\text { começou e termi- } \\
\text { nou pelo NÃO }\end{array}$ & $\begin{array}{l}\text { - Muito confusa e apelativa. } \\
\text { - Equivocada: Mostrava que todos } \\
\text { os problemas da violência seriam } \\
\text { resolvidos com a proibição da comer- } \\
\text { cialização. } \\
\text { - Apelativa: Muitos depoimentos com } \\
\text { artistas e moças em cadeiras de rodas. }\end{array}$ & $\begin{array}{l}\text { - Informativa: Explicava melhor sobre } \\
\text { os direitos dos cidadãos e que a proi- } \\
\text { bição tiraria um direito adquirido. } \\
\text { - Mostrava a realidade da inoperância } \\
\text { do Estado na questão da segurança. } \\
\text { - Mostrava que a proibição não } \\
\text { acabaria com o tráfico e nem com a } \\
\text { violência. } \\
\text { - Não usou artistas para persuadir. } \\
\text { - Mais racional e mais coerente. }\end{array}$ \\
\hline $\begin{array}{l}\text { MudanÇa DE } \\
\text { Atitude }\end{array}$ & $\begin{array}{l}\text { Eleitor que } \\
\text { começou pelo SIM } \\
\text { e terminou com o } \\
\text { NÃO. }\end{array}$ & $\begin{array}{l}\text { - A campanha do SIM, mostrou } \\
\text { muitos artistas e os argumentos não } \\
\text { foram convincentes. }\end{array}$ & $\begin{array}{l}\text { - Mostrou ser necessário ter a liber- } \\
\text { dade de escolher e que os bandidos } \\
\text { continuarão a ter armas ilegais. }\end{array}$ \\
\hline \multirow[b]{2}{*}{$\begin{array}{l}\text { FORMAÇÃO DE } \\
\text { ATITUDE }\end{array}$} & $\begin{array}{l}\text { Indeciso, que ter- } \\
\text { minou pelo SIM. }\end{array}$ & $\begin{array}{l}\text { - Mostrou que acontecem muitos } \\
\text { acidentes com crianças. }\end{array}$ & $\begin{array}{l}\text { - Não convenceu, pois a única finali- } \\
\text { dade das armas é matar. }\end{array}$ \\
\hline & $\begin{array}{l}\text { Indeciso, que ter- } \\
\text { minou pelo NÃO. }\end{array}$ & - Confusa, não esclarecia. & $\begin{array}{l}\text { - A "loirinha do NÃO" explicou mel- } \\
\text { hor o que aconteceria se houvesse a } \\
\text { proibição. } \\
\text { - Mostrou que os bandidos se sen- } \\
\text { tiriam mais à vontade se houvesse a } \\
\text { proibição. }\end{array}$ \\
\hline
\end{tabular}


to de todos, mas apenas das pessoas de bem, de tal forma que essa opção seria apenas abrir mão do direito de ter uma arma e de se proteger. Mas a informação sobre a perda do direito de se proteger portando uma arma ganhou relevância, sobretudo com a divulgação de notas sobre a inoperância do Estado na área de segurança. Os eleitores favoráveis ao NÃO aceitaram a conclusão de que o Estado não tiraria as armas dos bandidos, mas apenas dos cidadãos, tornando-os presas fáceis do crime.

Os dados qualitativos refletem os dados quantitativos. De acordo com Soares (2006), os dois argumentos do NÃO que apresentaram maior correlação com a certeza do voto foram: "Com a proibição o Governo estará tirando do cidadão o direito de se defender" e "Hoje posso não precisar de uma arma, mas se um dia eu precisar quero ter o direito de comprar"?

A propaganda consolidou minha opinião. Mostrou que quem quiser comprar uma arma deve ter esse direito de escolha e eu não quero perder o meu direto de poder escolher se quero ou não ter uma arma para me defender dos bandidos, já que a polícia é falha (Homem, classe A/B, mais de 50 anos, pelo NÃO).

[O Horário Eleitoral] mostrava a realidade da inoperância do Estado na questão da segurança e que a proibição não acabaria com o tráfico e nem com a violência (Mulher, classe A/B, mais de 50 anos, pelo NÃO).

Aquela loirinha do NÃO me explicou melhor o que aconteceria caso eu votasse no SIM. Antes eu queria votar no NÃO e meu filhou tentou me convencer a votar no SIM. Realmente eu pensei em votar dessa forma. Mas a "loirinha do NÃO" me mostrou que era melhor eu votar no NÃO e que os bandidos vão sempre existir. E eles conseguem armas através do contrabando e não comprando legalmente (Mulher, classe D, mais de 50, indecisa pelo NÃO).

[O Horário Eleitoral] explicava que era um direito nosso de nos defender dos bandidos e isso nos ajudaria a ter mais segurança já que o governo é falho nessa questão (Homem, classe B/C, 30 a 50 anos, indeciso, mas depois pelo NÃO).

[O Horário Eleitoral] informou-me que haverá ainda mais violência, pois os bandidos vão agir mais livremente, porque já vão saber antes que as pessoas não têm como se defender (Mulher, classe $\mathrm{B} / \mathrm{D}, 30$ a 50 anos, indecisa, mas depois pelo $\mathrm{NA} O)$.

O formato do programa da Frente pelo Direito à Legítima Defesa despertava nos telespectadores a percepção de autoridade, a sensação de que os seus produtores e aliados eram pessoas sérias e com conhecimento. Os participantes diziam "aprender", "se informar" com a campanha do NÃO. Possivelmente, resultado da decisão de adotar um apelo menos emocional e mais pragmático e ideológico.

De acordo com Boudon (1989), as pessoas tendem a recorrer a um especialista diante da necessidade de tomar uma decisão sobre algo que lhes parece uma "caixa preta". No caso do referendo das armas, foi possível perceber que os eleitores encontraram na âncora/jornalista da campanha do NÃO - sempre com uma postura séria, querendo denotar transparência e imparcialidade - um canal de conhecimento e de possibilidade de acesso a especialistas.

Em síntese, é possível verificar concordância entre os principais motivos para o voto - identificados pelas pesquisas qualitativa e quantitativa - e o principal mote da campanha "arma e a discussão da venda baseada em valores". Nos argumentos dos entrevistados descritos acima, também foi

\section{Figura 6}

\section{Efeito da Persuasão da Retórica da Frente Parlamentar pelo Direito da Legítima Defesa}

\section{Tempo $>>$}

IMAGINÁRIO SOCIAL---------CULTURA POLÍTICA----------HEGEMONIA------------CR-------CONJUNTURA $\rightarrow$ $\Uparrow$

Arma e a discussão da venda baseada em valores (54,9\%)

$\Uparrow$

Principal motivo para o voto 
possível perceber como a campanha ativou valores e percepções mais perenes como, por exemplo, a preocupação em perder um direito, a avaliação da ineficiência do Estado e a falta de confiança no mesmo.

\section{Conclusão}

O objetivo deste trabalho foi analisar as retóricas apresentadas pela Frente por um Brasil sem Armas e pela Frente pelo Direito à Legítima Defesa durante o Referendo das Armas, em outubro de 2005. Para isso, realizou-se uma análise de conteúdo dos programas eleitorais divulgados pelas duas campanhas. Avaliou-se também o efeito da propaganda na decisão do voto. Por entender que a metodologia qualitativa é um instrumental pertinente para a análise da recepção e do processamento das mensagens veiculadas pela mídia, optou-se pelo uso de entrevistas em profundidade, realizadas com 21 eleitores em Curitiba. Adotou-se, ainda, a técnica de painel, tendo sido cada participante entrevistado em três momentos distintos: antes do início da propaganda; durante o período de veiculação da propaganda; no instante posterior ao Horário Eleitoral, mas antes do dia da votação.

O conceito de Cenário de Representação Política - CR-P, desenvolvido por Venício Lima (2004), foi utilizado na análise do referendo. O argumento central era de que havia um CR-P favorável à campanha do SIM, oriundo do movimento pelo Estatuto do Desarmamento. Era possível identificar nos elementos constitutivos do CR-P - particularmente nas novelas e nos telejornais - fortes apelos ao desarmamento. Nesse contexto, tratava-se de uma unanimidade a aceitação do lema "menos armas, mais vidas".

De acordo com Lima (2004), aquela campanha afinada com o CR-P do momento teria mais chances de ser vitoriosa em um pleito. Ao longo deste trabalho, foi demonstrado como a Frente por um Brasil sem Armas se empenhou na construção de um discurso que concordasse e potencializasse os argumentos oriundos do movimento pelo Estatuto do Desarmamento. No entanto, a expectativa de vitória do SIM não se cumpriu. A estratégia da Frente por um Brasil Sem Armas não obteve sucesso em associar o referendo à campanha do
Estatuto do Desarmamento e ao Cenário de Representação, amplamente a seu favor. Tal estratégia foi inviabilizada pela ação da Frente pelo Direito da Legítima Defesa.

Ainda segundo Lima, a maneira de uma campanha vencer um pleito em que não esteja afinada com o CRP dominante é resgatar valores mais perenes na cultura política ou no imaginário social que possam contribuir para anular a vantagem do adversário. A campanha do NÃO refutou o argumento principal da Frente por um Brasil sem Armas ao ativar antigas percepções que os brasileiros têm a respeito do Estado. Na prática, a campanha do NÃO convenceu os eleitores de que a proibição da venda legal de armas e munições não reduziria a criminalidade e ainda deixaria o cidadão muito mais vulnerável ao crime, pois o Estado não conseguiria oferecer um serviço de segurança eficiente. Dessa forma, abrir mão do direito de ter arma significava tornar-se presa fácil do crime.

A campanha do NÃO usou a propaganda política negativa para polarizar a discussão e persuadir o eleitor. Com base na literatura internacional, é possível constatar que não há um consenso entre os pesquisadores sobre o efeito da propagada negativa na opinião pública, mas é cada vez maior o número de adeptos de que esse tipo de discurso serve para polarizar disputas, mas não para motivar os eleitores para o pleito. Comportamento semelhante foi verificado entre os eleitores brasileiros.

Em relação ao comportamento da audiên-cia, constatou-se que os eleitores que votaram pelo SIM usavam como justificativa os argumentos que vinculavam "arma e violência". Já os eleitores que decidiram pelo NÃO usavam como justificativa para o voto os temas sobre "a arma e a discussão da venda baseada em valores". Dessa forma, foi possível verificar que os discursos que receberam mais atenção das campanhas tiveram maior impacto na audiência.

A experiência com estudos de campanhas e comportamento eleitoral em referendos no Brasil ainda é muito restrita. Possivelmente, com a realização de novas consultas populares, novas oportunidades de estudo se abrirão. este artigo teve a pretensão de contribuir para esse estágio de pesquisa ainda tão inicial.

\section{Notas}


1 As iniciativas de publicação da UFMG e do Iser merecem destaque (ver Bibliografia).

2 A Pesquisa Datafolha de 21 de julho de 2005 apontava que $80 \%$ dos brasileiros concordavam com a proibição do comércio de armas de fogo e munição no país. Em setembro do mesmo ano, uma pesquisa Sensus/CNT mostrava que $72 \%$ adotavam tal postura.

3 Vale lembrar o projeto de lei número 4718/2004, que teve a sua origem na proposta apresentada pelo Conselho Federal da Ordem dos Advogados do Brasil. O documento prevê a regulamentação do artigo 14 da Constituição em matéria de plebiscito, referendo e iniciativa popular e tem como objetivo ampliar a participação da sociedade nas tomadas de decisão. A proposta foi apresentada na forma de anteprojeto de lei, elaborado pelo jurista e professor Fábio Konder Comparato. O projeto está em tramitação - lenta - no Congresso Nacional.

Para conhecer a teoria da agenda-setting, ver Azevedo (2004). Sobre a teoria da espiral do silêncio, ver Noelle-Neuman (1993).

5 Sobre a atitude e comportamento do Poder Executivo favorável à proibição do comércio de armas e munições, ver Anastásia et al. (2006) e Inácio (2006). "Vale assinalar que o Executivo atuou como ator central na configuração dos contextos decisórios, nos quais se decidiu sobre a proibição do comércio de armas [...]. A intensidade da preferência do Executivo pode ser indicada pelo movimento que este adotou no sentido de deslocar o tema para o centro da agenda legislativa. Evidência disso é o fato de que a matéria foi definida como prioridade na primeira convocação extraordinária do Congresso Nacional efetivada pelo governo Lula" (Anastásia et al., 2006, p. 20). Araújo e Santana (2006) descreveram o processo do referendo como "uma estratégia governista malograda”.

Sobre a atitude da mídia, ver Fuks e Novais (2006). Cabe fazer uma ressalva da atitude da revista Veja, que deu indícios de que preferia a não proibição do comércio de armas e munições.
8

Os graus de correlação entre o argumento em questão e a certeza do voto no SIM eram de 0,52 (escolaridade até $8^{\circ}$ série), 0,58 (escolaridade colegial completo ou não) e 0,69 (escolaridade superior completo ou não).

9 Os níveis de correlação entre a aceitação do argumento "hoje posso não precisar de uma arma, mas se um dia eu precisar quero ter o direito de comprar" e a certeza do voto em SIM são: -0,48(escolaridade até $8^{\circ}$ série), -0,59 (colegial completo ou não) e -0,78(superior completo ou não). Já a concordância com o argumento "com a proibição o Governo estará tirando o cidadão o direito de se defender" e a certeza o voto em SIM apresentaram os seguintes níveis de correlação: -0,37(escolaridade até $8^{\circ}$ série), -0,63 (colegial completo ou não) e -0,69(superior completo ou não).

\section{BIBLIOGRAFIA}

ANASTASIA, Fátima; INÁCIO, Magna \& NOVAIS, Raquel. (2006), "Referendo e democracia: perdas e ganhos", in (orgs.), Democracia e referendo no Brasil, Belo Horizonte, Editora da UFMG.

ANSOLABEHERE, S. \& IYENGAR, S. (1995), Going negative: bow political advertisements shrink and polarize the electorate. Nova York, Free Press.

ARAÚJO, Paulo \& SANTANA, Luciana. (2006), "O referendo sobre o comércio de armas: processo decisório, representação política e participação popular na democracia brasileira”, in Fátima Anastasia, Magna Inácio e Raquel Novais (orgs.), Democracia e referendo no Brasil, Belo Horizonte, Editora da UFMG.

AZEVEDO, Fernando Antônio. (2004), "Agendamento da política”, in Antônio A. C. Rubim (org.), Comunicação e política: conceitos e abordagens, Salvador, Edufba. da Região Metropolitana de Curitiba foram extraídos de um estudo elaborado pela Associação Brasileira de Empresas de Pesquisa - Abep, a partir da pesquisa LSE 2005 - Ibope Mídia (Disponível no site http://www.abep.org/codigosguias/Criterio_Brasil_2008.pdf, acessado em 23 de fevereiro de 2008).

\author{
.

.


"Estratégia de persuasão em eleições majoritárias: uma proposta metodológica para o estudo da propaganda eleitoral", in Rubens Figueiredo (org.), Marketing político e persuasão eleitoral, São Paulo, Fundação Konrad Adenauer.

FUKS, Mario \& NOVAIS, Raquel. (2006), "O referendo e a cobertura da imprensa: uma análise do ambiente informacional", in Fátima Anastacia, Magna Inácio e Raquel Novais (orgs.), Democracia e referendo no Brasil, Belo Horizonte, Editora da UFMG.

GARRAMONE, Gina. (1984), "Voter responses to negative political ads". Journalism Quartely, 61 (2): 250-259.

GREENBAUN, Thomas. (1998), The handbook for focus group research. Londres, Sage.

GUILHERMOPRIETO, Alma. (1993), "Obsessed in Rio". The New Yorker, 16, ago.

INACIO, Magna. (2006), "Implementando a agenda presidencial? A participação do Poder Executivo no referendo sobre as armas", in Fátima Anastacia, Magna Inácio e Raquel Novais (orgs.), Democracia e referendo no Brasil, Belo Horizonte, Editora da UFMG.

IYENGAR, Shanto. (1994), Is anyone responsible? How television frames political issues. Chicago, University of Chicago Press.

LAGE, Nilson. (2001), Ideologia e técnica da notícia. Florianópolis, Editora da UFSC.

LIMA, Venício A. (2004), "Cenário de Representação da Política, CR-P", in Antônio A. C. Rubim (org.), Comunicação e política: conceitos e abordagens, Salvador, Edufba.

LISSOVSKY, Maurício. (2006), "A campanha na tevê e a desventura do SIM que era Não", in Maria Mota e Samyra Crespo (orgs.), Referendo do SIM ao não: uma experiência da democracia brasileira. Rio de Janeiro, Iser (Comunicações do Iser, n. 62).

MERTON, Robert. (1968), Social theory and social structure. Nova York, The Free Press.
McGUIRE, W. J. (1973), "Persuasion, resistance and a attitude chance", in W. Schramm (org.), Handbook of communication. Chicago, Rand McNally.

NOELLE-NEUMAN, Elizabeth. (1993), "Pesquisa eleitoral e clima de opinião". Revista Opinião Pública, 1 (2): 47-62, dez., Campinas.

SOARES, Gláucio Ary Dillon. (2006), "Do sim ao não: uma análise das pesquisas de tracking", in Maria Mota e Samyra Crespo (orgs.), Referendo do SIM ao não: uma experiência da democracia brasileira. Rio de Janeiro, Iser (Comunicações do Iser, n. 62).

VREESE, Claes \& SEMETKO, Holli. (2002), "Cynical and engaged: strategic campaign coverage, public opinion, and mobilization in a referendum". Communication Research, 29 (6): 615-641. 
O REFERENDO DAS ARMAS NO BRASIL: ESTRATÉGIAS DE CAMPANHA E COMPORTAMENTO DO ELEITOR

\section{Luciana Fernandes Veiga e San-} dra Avi dos Santos

Palavras-chave: Referendo no Brasil; Referendo das armas; Retórica em referendos; Comportamento do eleitor; Pesquisa qualitativa.

O Referendo das Armas é abordado neste artigo com ênfase na estrutura das retóricas das campanhas televisivas e no comportamento eleitoral. Os objetivos são: a) analisar como as frentes que representavam a dualidade do pensamento - Frente Parlamentar por um Brasil Sem Armas e Frente Parlamentar pelo Direito da Legítima Defesa - construíram seus discursos veiculados no Horário Eleitoral; e b) avaliar como os eleitores utilizaram tais argumentos na definição do voto. Para isso, foram analisados os programas do Horário Eleitoral veiculados no período de 1 a 20 de outubro de 2005. Para o estudo da retórica, seguiu-se a metodologia desenvolvida pelos pesquisadores do Doxa/Iuperj , após uma pequena adaptação. Para a análise do comportamento do eleitor, aplicou-se a técnica de painel com entrevistas em profundidade.
BRAZILIAN WEAPONS REFERENDUM: CAMPAIGN STRATEGIES AND BEHAVIOR OF THE VOTER

\section{Luciana Fernandes Veiga and Sandra Avi dos Santos}

Keywords: A referendum in Brazil; The Brazilian weapon referendum; Rhetoric in referendums; The behavior of electors; Qualitative research.

The Referendum of Weapons is discussed in this article with emphasis on the rhetorical structure of the television campaigns and in the electoral behavior. The goals are: a) examine how the organizations which represented the duality of thought - Parliamentary Front for a Brazil without weapons and Parliamentary Front for the Right to self-defense elaborated their speeches for advertisement, broadcasted on Election Time, and b) assess how voters used such arguments in the vote definition. Therefore, the Election Time programs broadcasted from October 1 st to the 20th, 2005 were analyzed. The methodology for the analysis of campaigns developed by researchers of Doxa/Iuperj (2000) was used for the study of rhetoric, after a minor adjustment. For the analysis of the behavior of the voter, a panel with in-depth interviews was applied.
LE RÉFÉRENDUM DES ARMES AU BRÉSIL: STRATÉGIES DE CAMPAGNE ET COMPORTEMENT DE L'ÉLECTEUR

\section{Luciana Fernandes Veiga et San- dra Avi dos Santos}

Mots-clés: Référendum au Brésil; Référendum des armes; Rhétorique en référendums; Comportement de l'électeur; Recherche qualitative.

Cet article aborde le Référendum des Armes, en mettant l'accent sur la structure rhétorique des campagnes télévisuelles et sur le comportement électoral. Les objectifs sont: a) examiner comment les organisations qui représentent la dualité de la pensée - Front parlementaire pour un Brésil sans armes et Front parlementaire pour le droit à l'autodéfense - ont construit leurs discours pour la publicité télévisée sur le référendum; et, b) évaluer comment les électeurs ont utilisé de tels arguments dans la définition du vote. Les auteurs ont, ainsi, étudié les programmes de propagande électorale télévisés du $1^{\text {er }}$ au 20 octobre 2005. La méthodologie de l'analyse des campagnes, développée par les chercheurs de la Doxa/ Iuperj (2000), a été adaptée et utilisée pour l'étude de la rhétorique. Pour l'analyse du comportement des électeurs, une technique de panneaux avec des interviews en profondeur a été employée. 